\title{
New Hypoglycaemic Drugs for the Treatment of Diabetes Mellitus and Its Complications: The Future is coming.
}

\section{Alberto Martínez-Castelao*}

Nephrology Department, Bellvitge's University Hospital, Spain

*Corresponding author: Alberto Martínez-Castelao, Nephrology department, Bellvitge's University Hospital, Barcelona, Spain, Tel: +34-932607602; E-mail: albertomcastelao@gmail.com

\section{Review Article \\ Volume 4 Issue 1}

Received Date: February 07, 2019

Published Date: March 01, 2019

DOI: $10.23880 / o a j u n-16000157$

\section{Abstract}

Diabetes mellitus (DM) has become a growing epidemic over the last few decades. The International Diabetes Federation (IDF) estimates that more than 640 million people will be affected by this condition by 2040 . Although the incidence of some of the cardio-vascular complications of DM seems to have shown a decrease over the last years, DM continues to be the main cause of kidney disease, which will require renal replacement therapy (RRT).

Many different studies have tried to demonstrate, not always effectively, that the application of clinical practice guidelines and consensus documents may help to stop the onset and progression of the vascular and renal complications of DM. Numerous molecules have also emerged in recent years to improve both the management of DM as well as the onset of micro and macro vascular complications.

In this review, we will provide a summary of the metabolic, vascular and renal effects of DPP-4 inhibitors, Glucagon-likePeptide 1 Receptor agonists (GLP-1a) and sodium-glucose co-transporter inhibitors (SGLT2i), especially in patients with diabetic kidney disease with decreased renal function. These new molecules seem to open favorable perspectives in the integrated and multi factorial care of the DM patients.

Keywords: Diabetic kidney disease; Cardio-Vascular Disease; DPP-4 Inhibitors; GLP-1 Agonists; SGLT2 Inhibitors; Mortality; End-Stage Renal Disease; Renal Replacement Therapy

Abbreviations: DM: Diabetes mellitus, MODY: Maturity Onset Diabetes of the Young, DKD: Diabetic Kidney Disease, CV: Cardiovascular, RRT: Renal Replacement Therapy, TZD: Thiazolidinediones, iDPP4: Dipeptidyl-Peptidase 4, GLP-1: Glucagon-like peptide 1, IDF: International Diabetes Federation.

\section{Introduction}

Diabetes mellitus (DM) has been a growing opidemia in the last decades, confirming the predictions of World Health Report in 1997 that estimated progressive growth of the disease during the following 20 years [1]. 
The prevalence of diabetes in USA by 2012 was $14 \%$ ( $9 \%$ of cases with known diagnosis), but it was especially remarkable and alarming that there was a $38 \%$ population in situation of prediabetes [2]. If such a trend continues by 2050 , one out of every 3 adults in the USA will be diabetic [3]. The increase in the prevalence of DM has occurred especially at the expense of DM type 2 (DM2), due to increased obesity and changes in lifestyle [4]. The health cost of DM in 2012 in USA amounted to 245,000 million dollars, including the repercussion derived from the lack of productivity of patient with complications. Although between 1990 and 2010 the population of diabetics in USA grew by $27 \%$, the percentage of complications linked to DM decreased: amputations, from $22.6 \%$ to $18.8 \%$; advanced renal failure, from $13.7 \%$ to $6.1 \%$; myocardial infarction, from $3.8 \%$ to $1.8 \%$ and stroke, from $3.1 \%$ to $1.5 \%$ [5]. These facts are probably due to an improved diagnosis and care of both DM as of its complications.

The globalization of DM is a world health problem, with an increase in the incidence and prevalence that include variants such as gestational diabetes and DM type MODY (Maturity Onset Diabetes of the Young), that is, diabetes of mature age that occurs in the young [6,7]. In Spain, the Di@bet.es study, carried out in 100 centers with wide geographical distribution, found some disorder of the hydrocarbon metabolism in about $30 \%$ of the population studied [8]. The prevalence of DM, adjusted for age and gender, was 13.8\% (95\% CI: $12.8-14.7 \%$ ), and a $6 \%$ (95\% CI: $5.4-6.7 \%$ ) of the population was not aware of being diabetic. The socioeconomic impact of DM and its complications in our country is important, with an estimated global cost of $€ 2132$ /patient/year if microand macro vascular complications are present [9] a reduction in chronic kidney disease stage 5 (CKD-5) may save between 15 and 25 million euros in 3 years in the Canary Islands [10].

The presence of elevated excretion of urine albumin and the progression toward proteinuria have been the most common forms of clinical expression of diabetic nephropathy. However, in recent years there has been a growing description of the progression toward renal failure without developing proteinuria [11] which has led to postulate the existence of a "non-proteinuric phenotype" [12]. Tervaert, et al. [13] proposed in 2010 a new histopathological classification of renal lesions in DM, insisting on the finding of tubulo-interstitial and/or vascular lesions in the absence of glomerular lesions as an initial form of renal involvement. Thus, the classic concept of diabetic nephropathy, that requires a renal biopsy, has changed to a more generic concept of "diabetic kidney disease" (DKD).

\section{How to Prevent Diabetic Kidney Disease (DKD) and Cardiovascular (CV) Disease in DM?}

The Consensus Documents as well as the current Clinical Practice Guidelines for the prevention and management of DM and DKD include several specific aspects: to optimize the control of glycaemia and blood pressure, interventions to reduce renal and CV risk factors, healthy life style with exercise appropriate to the situation of each patient, adequate protein and sodium intake, adequacy of diet carbohydrates, cessation of smoking, lipid monitoring, treatment with Inhibitors of Renin Angiotensin-Aldosterone System (RAAS-I), and two other key points: optimization of hypoglycaemic drugs to the renal function of each patient throughout the evolution of CKD and a coordinated multifactorial and multidisciplinary control to prevent the progression of micro and macro vascular damage [14-21].

Despite all these recommendations and strategies, DKD remains the first cause of advanced CKD that will require Renal Replacement Therapy (RRT). The need to reduce the progression of micro and macrovascular damage in DM has led to multicenter studies including vascular and renal targets. The searches for new agents that have been evaluated in numerous clinical trials, as well as the use of specific therapies trying to stop the progression of vascular and renal damage are now mandatory.

There are numerous studies on new drugs that have been considered candidates to be subsequently translated to the clinical scenario but only some of them have demonstrated a positive impact on the management of DM and its complications.

\section{New Hypoglycaemic Drugs: Beyond the Hypoglycaemic Effect}

In many of our DM patients the control of blood glucose, BP and proteinuria are not enough to prevent the occurrence of DKD and the progression of the renal damage. The pharmaceutical industry and researchers are vigorously trying to find new alternatives, in such a way that the investigation of new molecules is one of the most intense development fields in recent years. Currently there are more than hundred studies with new molecules (www.clinicaltrials.gov) and there are in the clinical practice new drugs for the management of 
hyperglycaemia and its effects related and nonrelated to its hypoglycaemic effect.

1. Some hypoglycemic agents have shown to have renoprotective effects, independently of its effect on glucose concentration. Numerous studies with agonists of receptor activated by proliferators of the Gamma perixosomes, (PPAR- $\delta$ ) or thiazolidinediones (TZD) have shown to be able to reduce albuminuria $[22,23]$. The post hoc analysis of the study PROACTIVE (Prospective Pioglitazone Clinical Trial in Macro-Vascular Events), showed a greater GFR reduction in the group treated with pioglitazone than with placebo [24]. A meta-analysis that included 15 studies with pioglitazone and rosiglitazone), including 2860 patients, found significant reductions in albuminuria. However, the harmful cardiovascular effects such as increased hydro saline retention, have limited the use of these agents [25].

Aleglitazar is an agent with double effect PPAR $\alpha$ and $\delta$, that should have anti-inflammatory effects, improvement of both lipid profile and blood glucose level. The clinical trial that was intended shows these effects, as well as a potential reduction of proteinuria, but was suspended prematurely due also to adverse $\mathrm{CV}$ effects, similar to those observed in the previous studies with TZD [26].

2. The introduction of Dipeptidyl-Peptidase 4 (iDPP4) inhibitors has been a revolution in the management of hyperglycaemia in DM, due to the "incretin" effect of these drugs. DPP-4 is the enzyme that regulates the degradation of Glucagon-like peptide 1 (GLP-1), an incretin released in the intestine in response to food intake to stimulate insulin and suppreses glucagon production. Numerous studies have tried to show the beneficial vascular and renal effects of vildagliptin, sitagliptin, saxagliptin, alogliptin, linagliptin and teneligliptin.

A combined analysis of four phase III studies that included 217 patients with DM2 and diabetic nephropathy, showed beneficial effects of linagliptin, (the only iDPP-4 together with teneligliptin that does not require dose adjustment in renal failure), in reducing proteinuria by $32 \%$, regardless of the effect on $\mathrm{HbA} 1 \mathrm{c}$ [27].
Subsequently, the MARLINA study (Microalbuminuria and Renal Efficacy with Linagliptin) [28] tested the efficacy of single dose of $5 \mathrm{mg} /$ day of linagliptin in patients with DM2 and nephropathy. Linagliptin was only able to slow down the albuminuria in the group of "responders", (11.1\% of the Patients), but not in the overall of patients treated with the drug [29]. The CARMELINA trial has demonstrated a reduction in the UACR but not advantages on the CV outcomes in patients treated with linagliptine [30]. The SAVOR-TIMI study showed reduction of albuminuria in only $11.8 \%$ of patients who received saxagliptin and had available the albumin/creatinine ratio in urine [31].

\section{Agonists of GLP1 Receptor (Tables 1 \& 2)}

These kinds of drugs have the same incretin effect we have described when talking for DPP-4 inhibitors. In the last years different clinical trials have been published, with regards to the actions of liraglutide (LEADER) [32], semaglutide (SUSTAIN 6) [33], dulaglutide (AWARD-7) [34] or albiglutide (HARMONY) [35]. In these trails positive effects on microalbuminuria, proteinuria and/or $\mathrm{CV}$ events have been demonstrated. These drugs may be administered whit caution to patients with an estimated Glomerular Filtration Rate (eGFR) less than 60 $\mathrm{mL} / \mathrm{min} / 1,73 \mathrm{~m} 2$. Liraglutide and dulaglutide have been approved to be used in DKD with an eGFR above 15 $\mathrm{mL} / \mathrm{min} / 1,73 \mathrm{~m} 2$. The administration to patients with DM and eGFR less than $15 \mathrm{~mL} / \mathrm{min} / 1,73$ is still waiting to be proved in such patients but the positive results on renal and $\mathrm{CV}$ effects are promising.

\section{Na-Glucose Co-Transporter Inhibitors Type 2 (SGLT2i). (Tables $1 \&$ 2).}

SGLT2 inhibitors represent one of the most promising therapeutic novelties in the management of DM. The various SLGT receptors are widely distributed but with variations between the various organs. The SGLT2 are mainly located in the kidney. In the kidney, the glucose filtered at the glomerular level is totally reabsorbed by the tubules through SGLT2. The SGLT2i act on the proximal renal tubules preventing the tubular reabsorption of glucose and favoring its elimination in urine.

\begin{tabular}{|c|c|c|c|}
\hline CV morbidity \& mortality & Agent & MACE & CV mortality \\
\hline SAVOR & Saxagliptin & - & - \\
\hline EXAMINE & Alogliptin & - & - \\
\hline TECOS & Sitagliptin & - & - \\
\hline ELIXA & Lixisenatide & - & - \\
\hline LEADER & Liraglutide & $13 \%$ & $22 \%$ \\
\hline
\end{tabular}




\begin{tabular}{|c|c|c|c|}
\hline SUSTAIN 6 & Semaglutide & $26 \%$ & - \\
\hline AWARD 7 & Dulaglutide & - & - \\
\hline HARMONY & Albiglutide & - & $38 \%$ \\
\hline EMPA-REG & Empagliflozin & $14 \%$ & Start RRT \\
\hline Renal Events & Progression MAlb & Creatinine doubled & - \\
\hline LEADER & - & RR 22 $\%$ & - \\
\hline SUSTAIN 6 & - & RR 14 \% & RR 14 \% \\
\hline EMPA-REG & RR 14 $\%$ & RR 14 \% & \\
\hline
\end{tabular}

Table 1: Cardiovascular morbidity, mortality and renal events in recent studies with new hypoglycaemic agents.

\begin{tabular}{|c|c|c|c|c|c|c|}
\hline & $\begin{array}{c}\text { EMPA-REG } \\
(\mathrm{N}=7.020) \mathrm{N}=\mathrm{HR} \\
(95 \% \mathrm{CI})\end{array}$ & $P$ value & $\begin{array}{c}\text { LEADER }(\mathrm{N}=9.340) \\
\text { HR }(95 \% \mathrm{CI})\end{array}$ & $P$ value & $\begin{array}{c}\text { SUSTAIN-6 } \\
(\mathrm{N}=3.297) \mathrm{HR} \\
(95 \% \mathrm{CI})\end{array}$ & $P$ value \\
\hline Retinopathy & - & - & $1,15(0,87 ; 1,52)$ & 0.33 & $1,76(1,11 ; 2,78)$ & 0.02 \\
\hline $\begin{array}{c}\text { Incident or worsening } \\
\text { nephropathy }\end{array}$ & $0,61(0,53-0,70)$ & $<0.001$ & $0,78(0,67-0,92)$ & 0,003 & $0,64(0,46-088)$ & 0.005 \\
\hline $\begin{array}{c}\text { Progression to } \\
\text { proteinuria }\end{array}$ & $0,62(0,54 ; 0,72)$ & $<0,001$ & $0,74(0,60 ; 0,91)$ & n.s. & $0,54(0,37 ; 0,77)$ & $<0.001$ \\
\hline S creatinine doubled & $1,15(0,87 ; 1,52)$ & $<0.001$ & $0,88(0,66 ; 1,18)$ & n.s. & ,28 $(0,64 ; 2,58$ & 0.48 \\
\hline $\begin{array}{c}\text { Starting Renal } \\
\text { Replacement Therap. }\end{array}$ & $0,56(0,39 ; 0,79)$ & $<0.001$ & $0,88(0,66 ; 1,18)$ & n.s. & $1,28(0,64 ; 2,58)$ & 0.45 \\
\hline $\begin{array}{c}\text { Death due to renal } \\
\text { disease }\end{array}$ & - & - & $1,59(0,52 ; 4,87)$ & n.s. & - & - \\
\hline
\end{tabular}

Wanner C, et al. [37] and supplementary appendix; Marso, SP, et al. [33]; Presented at the American Diabetes Association 2016 76th Scientific Sessions, Session 3-CT-SY24. 13 June 2016, New Orleans, LA, USA; Marso SP, et al. [33] and supplementary appendix.

Table 2: Micro vascular results in EMPA-REG OUTCOME, LEADER and SUSTAIN-6 studies.

At the present time we have the possibility of using canagliflozin, dapagliflozin and empagliflozin, but other iSGLT2 are under development. The EMPA-REG study included 7028 patients with DM2, of whom 2345 received empagliflozin $10 \mathrm{mg}$ /day; 2348 received empagliflozin 25 $\mathrm{mg} /$ day and 2333 were the placebo group [36]. The study showed a significant decrease in $\mathrm{CV}$ episodes in all patients on empagliflozin (490 from 4687 patients, 10.5\%) versus placebo (282 in 2333, 12.1\%), RR 0.86, p $<0.001$.

The secondary objective was achieved in 599 of 4687 patients $(12.8 \%)$ in the empagliflozin group and in 333 of 2333 patients $(14.3 \%)$ in the placebo group, RR $0.62, \mathrm{p}<$ 0.001. After publication of the study EMPAREG, the results of the EMPA-REG Renal Study were analyzed. These were focused on the renal effects of treatment with empagliflozin at doses of 10 or $25 \mathrm{mg} /$ day in the 7028 patients with DM2 and various degrees of kidney disease [37]. The final analysis have shown that empagliflozin, both at doses of 10 and $25 \mathrm{mg} /$ day, was associated with a significant reduction of renal targets: progression from micro to proteinuria, reduction of the risk of a composite goal of serum creatinine duplication, initiation of renal replacement therapy, death of patient. The results of the study suggest beneficial CV effects beyond the action on glycaemic control.

The results EMPA-REG study referring to empagliflozin's effects in patients with established CV disease and chronic kidney disease (GFR $<60$ $\mathrm{mL} / \mathrm{min} / 1.73 \mathrm{~m} 2$ ) have been reported more recently. These results have shown a decrease in the relative risk of mortality (RR 0.71 ) of $29 \%$ for all categories of GFR and albuminuria, including patients with GFR $<60$ $\mathrm{mL} / \mathrm{min} / 1.73 \mathrm{~m} 2[37,38]$.

Very recently we have known the results of the CANVAS Program with Canagliflozin. The CANVAS program integrates data from two clinical trials including 10,142 patients with DM2 and high CV risk. The participants in each study were randomized to receive treatment with canagliflozin 100 or $300 \mathrm{mg} /$ day orally, or 
placebo. The mean follow-up was 188.2 weeks. The main objective was a c composite of $\mathrm{CV}$ death, non-fatal myocardial infarction, or non-fatal stroke. The mean age was 63.3 years and the mean duration of DM was 13.5 years. A $65.6 \%$ of patients had a previous history of CV disease. The main objective was reached in 26.9 vs. 31.5 of participants per 1000 patients/year; RR, 0.86; p < 0.001 for non-inferiority, $\mathrm{p}=0.02$ for superiority. The renal effects did not show statistical significance, but it showed a possible benefit of canagliflozin on the progression of albuminuria (RR, 0.73) and the $40 \%$ reduction in a composite goal of GFR, need for RRT, death of renal cause (RR, $0.60,95 \%$, CI: 0.47-0.77).

The results also showed an increase in the risk of distal amputations (6.3 vs. 3.4 participants per 1000 patients/year; RR 1.97; 95\% CI, 1.41-2.75). Although in the multivariate analysis the risk factors for amputations were: antecedents of previous amputations (HR: 20.9 [14.2-30.8]), peripheral vascular disease (HR: 3.1 [2.24.5]), male sex (HR: 2.4 [1.6-3.5]), autonomic neuropathy (HR: 2.1 [1.4-2.6]), HbA1c>8\% (HR: 1.9 [1.4-2.6]), treatment with canagliflozin (HR: 1.8 [1.3-2.5]), and presence of cardiovascular disease (HR: 1.5 [1.0-2.3]). The authors have concluded that canagliflozin decreases the risk of CV episodes, although with an increased risk of distal amputations [39].

The publication of renal effects and long-term CV outcomes of the CREDENCE study is pending. CREDENCE is a Randomized, Double-blind, Placebo-controlled, Parallel-group, Two-arm, Multicenter Study to Assess the Efficacy of Canagliflozin on End Stage Kidney Disease and Vascular Death in Subjects with Type 2 Diabetes Mellitus and Nephropathy $[40,41]$. This is the first clinical trial with iSGLT2 that includes a primary renal endpoint (initiation of renal replacement therapy, doubling of serum creatinine and renal or cardiovascular death). The study includes patients with albuminuria $>300 \mathrm{mg}$ and eGFR between 30 and $90 \mathrm{~mL} / \mathrm{min} / 1.73 \mathrm{~m} 2$.

The renal and CV effects of dapagliflozin have also being studied in numerous trials and studies. Kohan et al. have published a meta-analysis of 12 studies including 4545 patients with DM2 with durations greater than 24 weeks. He has reported transient decrease in the GFR, and no change after 108 weeks of follow-up and with few adverse effects [42].

Also recently we have known the results of the Study CVD-REAL World Nordic [43]. This is a global analysis performed by the national registries of Denmark, Norway and Sweden, dividing patients into two groups: those treated de novo with either dapagliflozin $(n=10,227)$ or with iDPP-4 ( $\mathrm{n}=30,681)$, the average age was 62 years and $23 \%$ had history of CV disease. As compared to iDPP4, Dapagliflozin was associated with lower risk of major CV episodes (RR0.79), heart failure (RR 0.62) or mortality from any cause (RR 0.44).

The results of the study DECLARE (DECLARE-TIMI58), which evaluates the incidence of CV events: CV mortality, myocardial infarction or cerebral vascular accident, in patients with DM2 treated with dapagliflozin $10 \mathrm{mg} /$ day has been very recently published. Dapagliflozin did not result in a higher or lower rate of MACE than placebo but did result in a lower rate of cardiovascular death or hospitalizations for heart failure [44].

The results so far available from studies with GLP1 agonists and iSGLT2, are in favor that both can reduce the incidence of ESRD. However, important limitations persist: studies with specifically "renal" main objectives must be designed. Secondly, the results regarding nephroprotection with GLP1 agonists may aid us to answer this open question that must be clarified in future trials and studies. The nephrologists are committed to acquire experience in the management of both types of drugs. We also need to answer the question on how the SGLT2i can act in patients with DKD and an eGFR below 45 or $30 \mathrm{~mL} / \mathrm{min} / 1,73 \mathrm{~m} 2$. Likewise, the possible CV benefits should be clarified as well as renal effects in the general population with DM and not only in high-risk CV groups included in the studies so far carried out. Finally, the high cost barrier of these drugs may be balanced against the possible benefits obtained.

\section{Conclusion}

DM continues to be the most frequent cause of advanced CKD in our environment, despite the stabilization in its frequency as a cause of stage 5 CKD in the last years. The promising results obtained with the new hypoglycaemic agents and others that will gradually appear will help us to a more adequate management of the patient with DM and to successfully face the future in the prevention and treatment of vascular and renal disease in patients with DM. We believe that these new molecules, handled early and adequately to the renal function will contribute to decrease the incidence and prevalence of DKD, together with the application of other well-known classic multi factorial and multidisciplinary standards. 


\section{Open Access Journal of Urology \& Nephrology}

\section{References}

1. World Health Organization. The world health report 1997.

2. Menke A, Casagrande S, Geiss L, Cowie CC (2015) Prevalence of and trends in DM among adults in United States, 1988-2012. JAMA 314(10): 1021-1029.

3. Polonsky KS (2012) The past 200 years in diabetes. N Engl J Med 367(14): 1332-1340.

4. Martínez-Castelao A, Navarro-González JF, Górriz JL, de Alvaro F (2015) The concept and the epidemiology of diabetic nephropathy have changed in recent years. J Clin Med 4(6): 1207-1216.

5. Gregg EW, Li Y, Wang J, Burrows NR, Ali MK, et al. (2014) Changes in diabetes-related complications in the United States, 1990-2010. N Engl J Med 370: 1514-1523.

6. Danaei G, Finucane MM, Lu Y, Singh GM, Cowan MJ, et al. (2011) National, regional, and global trends in fasting plasma glucose and diabetes since 1980: Systematic analysis of health examination surveys and epidemiological studies with 370 country-years and 207 million participants. Lancet 378(9785): 3140.

7. Abraham TM, Pencina K, Pencina MJ, Fox CS (2015) Trends in diabetes incidence: the Framingham Heart Study. Diabetes Care 38(3): 482-487.

8. Soriguer FR, Goday A, Bosch-Comas A, Bordiú E, CallePascual E, et al. (2012) Prevalence of diabetes mellitus and impaired glucose regulation in Spain: The Di@bet.es Study. Diabetologia 55: 88-93.

9. Mata M, Antoñanzas F, Tafalla M, Sanz P (2002) The cost of type-2 diabetes in Spain: The CODE-2 study. Gac Sanit 16(6): 511-520.

10. Lorenzo V, Boronat M (2010) End stage renal disease associated with diabetes in the Canary Islands: a public health problem with significant human suffering and high economic costs. Nefrologia 30(4): 381-384.

11. Dwyer JP, Lewis JW (2013) Nonproteinuric diabetic nephropathy: when diabetics don't read the textbook. Med Clin N Am 97(1): 53-58.
12. Porrini E, Ruggenenti P, Mogensen CE, Barlovic DP, Praga M, et al. (2015) Non-proteinuric pathways in loss of renal function in patients with type 2 diabetes. Lancet Diabetes Endocrinol 3(5): 382-391.

13. Tervaert TW, Mooyaart AL, Amann K, Cohen AH, Cook HT, et al. (2010) Pathologic classification of diabetic nephropathy. J Am Soc Nephrol 21(4): 556-563.

14. Sociedad Española de Nefrología, Sociedad Española de Diabetes, Sociedad Española de Endocrinología, Sociedad Española de Medicina Familiar y Comunitaria, Documento de consenso sobre pautas de deteccióny tratamiento de la nefropatía diabética en España (1997). Nefrologia 17: 467-474.

15. Asociación Española de Nefrología Pediátrica (AENPED), Sociedad Española de Diabetes (SEDIAB), Sociedad Española de Endocrinología y Nutrición (SEEN), Sociedad Española de Hipertensión Aterial y Liga Española para la Lucha contra la Hipertensión Arterial (SEH-LELHA), Sociedad Española de Medicina Familiar y Comunitaria (SEMFYC), Sociedad Española de Medicina Rural y Generalista (SEMERGEN), Sociedad Española de Nefrología (SEN), Documento de consenso 2002 sobre pautas de detección, prevención y tratamiento de la nefropatía diabética en España (2002). Nefrologia 22: 521-530.

16. Alcázar R, Egocheaga MI, Orte L, Lobos JM, González Parra E, et al. (2008) SEN-semFYC consensus document on chronic kidney disease. Nefrologia 28(3): 273-282.

17. Martínez-Castelao A, Górriz JL, Segura-de la Morena J, Cebollada J, Escalada J, et al. (2014) Consensus document for the detection and management of chronic kidney disease. Nefrologia 34(2): 243-262.

18. Gómez-Huelgas R, Martínez-Castelao A, Artola S, Górriz JL, Menéndez E (2014) Consensus document on treatment of type 2 diabetes in patients with chronic kidney disease. Nefrologia 34(1): 34-45.

19. Bilo H, Coentrão L, Couchoud C, Covic A, De Sutter J, et al. (2015) Clinical practice guideline on management of patients with diabetes and chronic kidney disease stage $3 \mathrm{~b}$ or higher (eGFR $<45 \mathrm{~mL} / \mathrm{min}$ ). Nephrol Dial Transplant 30(S2): 1-142.

20. American Diabetes Association Standards of Medical Care in Diabetes-2017. Diabetes Care 40(S1): 1-142. 
21. Fioretto P, Steffes MW, Sutherland DE, Goetz FC, Mauer M (1998) Reversal of lesions of diabetic nephropathy after pancreas transplantation. $\mathrm{N}$ Engl J Med 339(2): 69-75.

22. Calkin AC, Giunti S, Jandeleit-Dahm KA, Allen TJ, Cooper ME, et al. (2006) PPAR-alpha and -gamma agonists attenuate diabetic kidney disease in the apolipoprotein E knockout mouse. Nephrol Dial Transplant 21(9): 2399-2405.

23. Bakris GL, Ruilope LM, McMorn SO, Weston WM, Heise MA, et al. (2006) Rosiglitazone reduces microalbuminuria and blood pressure independently of glycemia in type 2 diabetes patients with microalbuminuria. J Hypertens 24(10): 2047-2055.

24. Schneider CA, Ferrannini E, Defronzo R, Schernthaner G, Yates J, et al. (2008) Effect of pioglitazone on cardiovascular outcome in diabetes and chronic kidney disease. J Am Soc Nephrol 19(1): 182-187.

25. Sarafidis PA, Stafylas PC, Georgianos PI, Saratzis AN, Lasaridis AN (2010) Effect of thiazolidinediones on albuminuria and proteinuria in diabetes: a metaanalysis. Am J Kidney Dis 55(5): 835-847.

26. Clinical Trials.gov. A study of aleglitazar in type 2 diabetes patients with moderate renal impairment.

27. Cooper ME, Perkovic V, McGill JB, Groop PH, Wanner C, et al. (2015) Kidney disease end points in a pooled analysis of individual patient-level data from a large clinical trials program of the dipeptidyl peptidase 4 inhibitor linagliptin in type 2 diabetes. Am J Kidney Dis 66(3): 441-449.

28. Groop PH, Cooper ME, Perkovic V, Sharma K, Schernthaner G, et al. (2015) Dipeptidyl peptidase-4 inhibition with linagliptin and effects on hyperglycaemia and albuminuria in patients with type 2 diabetes and renal dysfunction: rationale and design of the MARLINA-T2D ${ }^{\mathrm{TM}}$ trial. Diab Vasc Dis Res 12(6): 455-462.

29. Groop PH, Cooper ME, Perkovic V, Hocher B, Kanasaki $\mathrm{K}$, et al. (2017) Linagliptin and its effects on hyperglycaemia and albuminuria in patients with type 2 diabetes and renal dysfunction: the randomized MARLINA-T2D trial. Diabetes Obes Metab 19(11): 1610-1619.

30. Rosenstock J, Perkovic V, Johansen OE, Cooper ME, Kahn SE, et al. (2019) Effect of Linagliptin vs Placebo on Major Cardiovascular Events in Adults With Type 2 Diabetes and High Cardiovascular and Renal Risk: The CARMELINA Randomized Clinical Trial. JAMA 321(1): 69-79.

31. Mosenzon O, Leibowitz G, Bhatt DL, Cahn A, Hirshberg B, et al. (2017) Effect of saxagliptin on renal outcomes in the SAVOR-TIMI 53 trial. Diabetes Care 40(1): 69-76.

32. Mann JFE, Ørsted DD, Brown-Frandsen K, Marso SP, Poulter NR, et al. (2017) Liraglutide and renal outcomes in type 2 diabetes. N Engl J Med 377(9): 839-848.

33. Marso SP, Bain SC, Consoli A, Eliaschewitz FG, Jódar E, et al. (2016) Semaglutide and cardiovascular outcomes in patients with type 2 diabetes. N Engl J Med 375(19): 1834-1844.

34. Tuttle KR, Lakshmanan MC, Rayner B, Busch RS, Zimmermann AG, et al. (2018) Dulaglutide versus insulin glargine in patients with type 2 diabetes and moderate-to-severe chronic kidney disease (AWARD7): a multicentre, open-label, randomised trial. Lancet Diabetes Endocrinol 6(8): 605-617.

35. Hernandez AF, Green JB, Janmohamed S, D'Agostino RB Sr, Granger CB, et al. (2018) Albiglutide and cardiovascular outcomes in patients with type 2 diabetes and cardiovascular disease (Harmony Outcomes): a double-blind, randomised placebocontrolled trial. Lancet 392(10157): 1519-1529.

36. Zinman B, Wanner C, Lachin JM, Fitchett D, Bluhmki E, et al. (2015) Empagliflozin, cardiovascular outcomes, and mortality in type 2 diabetes. $N$ Engl J Med 373(22): 2117-2128.

37. Wanner $\mathrm{C}$, Inzucchi S, Lachin JM, Fitchett $\mathrm{D}$, von Eynatten M, et al. (2016) Empagliflozin and progression of kidney disease in type 2 diabetes. $\mathrm{N}$ Engl J Med 375: 323-334.

38. Wanner C, Lachin JM, Inzucchi S, Fitchett D, Mattheus M, et al. (2018) Empagliflozin and clinical outcomes in patients with type 2 diabetes mellitus, established cardiovascular disease, and chronic renal disease. Circulation 137(2): 119-129.

39. Neal B, Perkovic V, Mahaffey KW, de Zeeuw D, Fulcher G, et al. (2017) Canagliflozin and cardiovascular and renal events in type 2diabetes. N Engl J Med 377: 644657. 
40. Clinical Trials.gov. Evaluation of the effects of canagliflozin on renal and cardiovascular outcomes in participants with diabetic nephropathy (CREDENCE). Identifier: NCT02065791.

41. Rizvi A, Hartaigh BÓ, Knaapen P, Leipsic J, Shaw LJ, et al. (2016) Rationale and design of the CREDENCE trial: Computed TomogRaphic evaluation of atherosclerotic DEtermiNants of myocardial IsChEmia. BMC Cardiovasc Disord 16(1): 190.

42. Kohan DE, Fioretto P, Tang W, List JF (2014) Longterm study of patients with type 2 diabetes and moderate renal impairment shows that dapagliflozin reduces weight and blood pressure but does not improve glycemic control. Kidney Int 85(4): 962-971.

43. Persson F, Nyström T, Jørgensen ME, Carstensen B, Gulseth HL, et al. (2018) Dapagliflozin is associated with lower risk of cardiovascular events and all-cause mortality in people with type 2 diabetes (CVDREAL Nordic) when compared with dipeptidase-4 inhibitor therapy: a multinational observational study. Diabetes Obes Metab 20(2): 344-351.

44. Wiviott SD, Raz I, Binaca MP, Mosenzon O, Kato ET, et al. (2019) Dapagliflozin and Cardiovascular Outcomes in Type 2 Diabetes. N Engl J Med 380(4): 347-357. 